Michael A. Neblo

\title{
DELIBERATION'S LEGITIMATION CRISIS: REPLY TO GLEASON
}

\begin{abstract}
Laurel Gleason contends that deliberative polling constrains the autonomy of participants and substitutes the ideas and agendas of "experts" for those of the deliberators. However, the format and informational constraints faced by participants in deliberative forums are no worse, and are in many ways better, than those faced by ordinary citizens. The real problem with deliberative polls is that if they were to become popular, it would be tempting for interest groups and partisan elites to create polls in which the constraints and briefing materials subtly tilted the participants in a desired direction. Public criticism of biased deliberative polls would, in turn, invite biased criticism of unbiased polls. In short, "policing" the quality of deliberative polls could recreate the very pathologies of real-world democratic discourse that the polls are designed to rectify. However, this problem is not insurmountable, because the participants themselves can police the proceedings by questioning the veracity and balance of the briefing materials.
\end{abstract}

In "Revisiting the Voice of the People,' Laurel Gleason (20II) prosecutes a systematic, lawyerly case against the normative and empirical underpinnings of Deliberative Opinion Polls (DOPs). I disagree with many of Gleason's specific criticisms, or at least the way that she formulates and interprets them. But those smaller disagreements should be understood in terms of my belief that the spirit of her critique is apt and even necessary. Gleason raises important concerns that need to be answered clearly and publicly, even if I think that most of them can be

Michael A. Neblo, neblo.i@osu.edu, Department of Political Science, The Ohio State University, I 54 N. Oval Mall, Columbus, OH 432 Io.

Critical Review 23(3): 405-4I9

ISSN o89I-38 I i print, I933-8007 online

(C) 2012 Critical Review Foundation http://dx.doi.org/Io. I080/o89I 38 I I.20I I.635874 
adequately answered with moderate adjustments to deliberative theory and practice.

To that end, I reconstruct what I take to be the central tension in applied deliberation research, and sketch some ideas for how to manage it. For the most part, I leave to Professor Fishkin the task of engaging the empirical details of Gleason's criticism of his project, focusing my comments on the larger conceptual issues. I conclude with suggestions for moving the broader research agenda on applied deliberation forward in light of the issues raised by her critique.

Gleason presses her case against deliberative polling in four main sections. She begins by arguing that, contrary to Fishkin's claims, deliberative polls do not produce more autonomous, more informed, or more considered opinions. In her final section, she sketches some worries about deliberative polling as a species of democratic reform. I begin with this last section so as better to explain my response to the other three.

\section{Evidentiary Standards for "Social Engineering"}

Gleason (2OI I, 387) admits that she is "rather brusque in [her] criticisms of deliberative polling," justifying the rough treatment on the grounds that deliberative polling is "an exercise in social engineering and, as such, should be subject to strict scrutiny with regard to its normative and empirical claims." The term "social engineering" certainly carries negative connotations, but it is not clear exactly what it means here, why deliberative polling should fall under this rubric, nor even why being a case of social engineering necessarily entails "strict scrutiny" —an allusion to the highest (and nearly insurmountable) judicial standard applied when some government action runs up against a fundamental right or a suspect class. Virtually every law, policy, and proposal for reform involves a degree of social engineering in the mundane sense of intentionally crafting or altering social institutions in the hope of improving outcomes. If so, then one would have to be committed to an especially reactionary form of Burkean conservatism to hold all cases of social engineering to standards of strict scrutiny.

The key question, then, becomes just how radical and risky the idea of deliberative polling really is. That question, in turn, depends on several others. For example, is the reform aimed primarily at altering our deepest commitments and principles, or merely adjusting some of the means to 
realize them? Fascist and communist social engineering, for example, sought to alter our deepest underlying commitments. However, many recent democratic reforms (e.g., sunshine laws, requiring public advice and comment, and expanding the franchise) were offered merely as better institutional interpretations of our existing democratic commitments. Similarly, the riskiness of proposed reforms depends in part on the reserve value of the status quo. Are we trying to eke out marginal improvements to something that is already functioning very well, or is the status quo dysfunctional enough that there is a lot of room for potential improvement and not as much room for things to get dramatically worse under likely scenarios? Finally, the risk associated with social change also depends on how scalable, gradual, adaptable, and reversible the proposed reform is. For example, a single-payer health care system (whatever its other merits) has to be implemented on a relatively large scale to realize its goals and, once implemented, is difficult to reverse without significant transition costs. Other reforms can be implemented gradually and locally, adapted to new considerations and experiences quickly, and reversed with relatively little disruption should the experiments fail to deliver on their promises.

Across these criteria, deliberative polling seems to be warranted, in principle. Deliberative polling seeks to help us better realize familiar democratic commitments, rather than to urge radically new ones. Many scholars, citizens, and elected officials believe that much standard public opinion is rooted in appalling ignorance. If so, then the ratio between possible improvement and possible damage does not seem unreasonable. Finally, DOPs and other mini-public forums are scalable, adaptable, and reversible at little cost compared to many other social and political reform proposals. None of this is to suggest that we need not carefully evaluate the normative and empirical track record of extant deliberative polls and other mini-publics. But I see little reason for regarding deliberative polling as a particularly radical proposal, and thus little reason for invoking a particularly radical burden of proof.

Gleason, though, spends very little time directly arguing the case for deliberative polling as a radical form of social engineering. Instead, she creates the impression that it is radical by first holding it to strict scrutiny-claiming that extant evidence cannot rule out every possible way that deliberation could go wrong, and failing to compare these possibilities to the problems of the status quo-before concluding that deliberative polls are a reckless social gamble. In effect, the argument 
becomes rhetorically circular by implicitly justifying the controversial standard of proof based on the results of applying that standard.

\section{The Autonomy of Deliberative Participants}

Gleason applies strict scrutiny with gusto, granting Fishkin no quarter in the standards of his evidence or charity in their interpretation. Functionally, strict scrutiny seems to mean that the considerable body of existing evidence Fishkin and others have assembled does almost nothing to shift the burden of proof to skeptics of deliberation. For example, in her discussion of social domination, Gleason completely dismisses evidence that participants widely report feeling that they were not dominated by others and were able to have their say more generally. She writes: "However, effective domination of the discussion would, one might think, be effective precisely because the dominators were suave enough that they did not create the perception of being domineering", (Gleason 20II, 377, emph. original). Strictly speaking, of course, this claim is true. But Gleason does not cite any evidence or particular reason to think that such suave dominators are especially prevalent in deliberative polling, nor that the rest of the participants are especially naive dupes. Using raw speculation to refuse any shift in the burden of proof, however, seems ironic given that Gleason summarily rejects participants' self-reports in the context of professing worries over respecting their autonomy.

Fishkin, moreover, did not stop at merely shifting the burden via the self-reports. He presented evidence (consistent with the findings of others, e.g., Neblo 2005) that members of traditionally advantaged groups do not speak or participate at higher rates than less advantaged groups, nor do they have disproportionate influence on other participants. Yet Gleason (20II, 377) argues that such facts are "relevant only if talkativeness [and other factors are] characteristic of socioeconomic groups, not of individuals." Hundreds of studies show that women, minorities, the poor, and less educated people are disadvantaged in countless ways in nearly every facet of social interaction. Yet the fact that in DOps none of these disadvantages emerge is irrelevant to comparing them to politics-as-usual? Ruling out the most common, malignantly systematic sources of inequality (active in nearly every other domain of life) is not enough to shift any burden to skeptics? Instead, it seems that deliberative 
scholars have to rule out an open-ended and operationally unspecified list of individual level characteristics that might lead to deliberative inequalities. It is not even clear that the implicit alternative here is a coherent burden to assume, much less a reasonable one to impose. ${ }^{1}$

Most of Gleason's criticisms follow some variation on this pattern of raising objections that are not so much wrong as underspecified in their content and over-applied in their force. If so, her larger argument rests squarely on warranting the strict scrutiny standard that I have argued is misapplied here. In a few cases, though, the problems in the argument run deeper. For example, Gleason (201 I, 374) asserts that DOPs impose "an impressive set of constraints on the participants." She goes on to discuss a few, and then very briefly considers one of Fishkin's arguments justifying them. But then she cuts the discussion short and concludes that "[i]n any event, however, constraints diminish autonomy" (ibid., 378).

This claim is misleading in at least two ways. First, political theory has long distinguished between liberty and license. Constraining me from punching someone else does not diminish my autonomy in any problematic sense, and it actually protects my potential victims' autonomy in a very important sense. In a similar way, having procedures and moderators that do not allow verbal bullying or even just filibustering can promote, rather than diminish, autonomy in the relevant sense. Any broad claim about constraints and autonomy that does not carefully account for this distinction equivocates on terms.

Second, many of the constraints put on deliberative procedures may be usefully regarded as "enabling" constraints. In chess, for example, the rule that prohibits me from moving my rook diagonally does not diminish my autonomy in any relevant way. Rather it actually enables me to engage in a meaningful social practice that would otherwise dissolve without the constraint. Most of the constraints that Fishkin imposes are not pure cases of enabling constraints in that they are not logically constitutive conditions of the social practice of deliberative polling. But some substantial constraints on who, when, how, and about what people speak are certainly practical preconditions of mini-publics. If everything is up for grabs, then mini-publics cannot help us manage the scale, scope, complexity, and power formations of general politics, and so can serve no distinctive function in a broader political system that already provides many less structured opportunities for participation.

I differ with Fishkin on some of the details of effective mini-publics. Indeed, I think that we should have a flexible menu of designs tailored to 
different purposes and environments. So I do not want to defend each of his choices, nor DOPs generally as either the best or only way to realize deliberative public consultation. However, it is one thing to claim that DOPs may not strike an optimal balance with respect to the flexibility afforded participants, and quite another to claim that Dops diminish participants' autonomy relative to their status quo participation in the policy process. The latter claim strikes me as extreme and implausible except in unusual cases. Thus, blanket arguments claiming that any significant structure on deliberation diminishes the participants' autonomy miss their mark and obscure the real tradeoffs at stake.

\section{Are Deliberative Participants Informed by the Process?}

The broader issue here comes to a head in Gleason's treatment of the role of experts and the organizers of deliberative polls. As with many other concepts, Gleason nearly always puts "expert" and its cognates in scare quotes. ${ }^{2}$ But how are we to interpret the scare-quotes? Are they meant to suggest that experts are unimportant in the policy process? Or to imply that Fishkin routinely fails to consult with an adequate range of experts? Or that those experts are acting dishonestly or otherwise undermining the process? Obviously there are potential problems in relying on experts. Indeed, deliberative polling is motivated in part by worries over the role of expertise in the way that public opinion forms under statusquo conditions (i.e., that citizens either proceed without the benefit of expert knowledge, cannot easily sort reliable expertise, or exclusively seek out expert opinions that confirm their biases). But Gleason does not acknowledge that there are any competing problems with failing to involve experts, offers no specific criticisms of Fishkin's use of them, no substantial comparison to their current role in status quo opinion formation, nor any suggestions for better managing the implicit tradeoffs. This way of posing the objection is not very helpful.

To be clear: I am highly sympathetic to the implied worry here, but I think that Gleason's setup impedes, rather than advances, our understanding of the issues at stake. So rather than continuing to press my criticisms, let me switch modes and attempt to reconstruct what I see as the major legitimate concern with deliberative polling and other mini-public forums. Almost ninety years ago, Walter Lippmann (I922, I44) crisply articulated the first crucial component of the problem: 
As congenital amateurs our quest for truth consists in stirring up the experts, and forcing them to answer any heresy that has the accent of conviction. In such a debate we can often judge who has won the dialectical victory, but we are virtually defenseless against a false premise that none of the debators has challenged, or a neglected aspect that none of them has brought into the argument.

Relative to most status-quo opinion formation, even minimally welldesigned deliberative forums greatly subsidize our access to experts, "stir them up" in perspicuous ways, and provide us with highly augmented resources to judge who has won the dialectical victory. Bracketing Lippmann's admittedly crucial caveat (for the time being), the enormous literature on deliberative polling (even beyond Fishkin's works) renders it implausible, except on the very strictest of strict scrutiny, to think that deliberative opinion will not tend to be more informed, better informed, and more considered, at least on average.

Online processing of the background materials and information in the sessions, combined with most citizens' low baseline of information, practically guarantees that their judgments will be based on substantially more information on average (Neblo 2000). And that is to say nothing of the direct evidence for the increased ability to recall information (e.g., Esterling et al. 20I I). The case for being "better informed" is, of course, less straightforward since it hinges on one's definition of better. However, again bracketing Lippmann's caveat for now, the average participant will have been exposed to a much wider range of information, arguments, and perspectives deemed relevant by experts and their fellow citizens than under status-quo conditions. And if central versus peripheral processing is an important criterion for "more considered" opinions, then only the most determined skeptic would doubt that deliberative opinion is more considered vis-à-vis standard public-opinion interviews. The average respondent to a phone poll has not devoted three minutes of central processing to many issues about which she will be asked. Countless tapes and transcripts of deliberative sessions show large numbers of participants routinely engaging in exchanges that could not be sustained via peripheral processing. And if one cares about the deliberative goals of forming and justifying public opinions in a distinctly public way, rather than merely aggregating private opinion, again, the prima facie evidence in favor of deliberative forums versus standard polling is overwhelming. 


\section{The Paradox of Protecting against Manipulation}

This précis of my reasoning is compressed and peremptory. ${ }^{3}$ But I am not trying to settle the empirical questions; I am, rather, making a prima facie case for why they should be seen as less crucial than Gleason portrays them. Criticizing deliberative polling more effectively requires shifting attention to a much more important and vastly weaker spot in the case for deliberative forums. If my sketch above is right, minimally well-designed deliberative forums will, in expectation, yield higher quality public opinion relative to relying on the ambient political culture. And this is likely to be the case even when we reintroduce Lippmann's worry over false premises and neglected considerations among elites, since we still have finite access and attention in our everyday political lives. However, within deliberative forums, the effects of being captured by false premises and neglected considerations are likely to be larger than under status-quo opinion formation, since the denser set of common influences on participants will induce more highly correlated errors. In itself, this issue is significant only to the extent that we are risk averse, and even then we would need to trade it off against the broader gains in expected opinion quality.

The more serious problem, though, becomes apparent when we recognize that correlated errors create powerful incentives for interest groups and partisan elites to try to manipulate deliberative forums. Their smaller scale and captive audience (i.e., their potential for correlated errors) make them an extremely high-leverage/low-cost way to try to influence policy, versus trying to move the broader political culture. And dramatically more so precisely to the extent that deliberative forums are more directly empowered or invested with the imprimatur of representing the authentic voice of the people. But if special interests could intervene to change the distribution of errors substantially, and we were not reliably able to know when they had succeeded, then the simple version of my argument for the presumptive superiority of deliberative opinion would collapse.

Most of the main elements in my critique of deliberative forums here are present in Gleason's article at least in some form. But the lawyerly approach that she adopts unintentionally waters down the force of her critique, making it difficult to see how specific elements combine in a way that are not merely additive. The potential for manipulation, in itself, is not a particularly powerful objection, since the ambient political 
culture is rife with manipulation. Similarly, the potential for correlated errors, in itself, is not a particularly powerful objection, since there are good reasons to think that the overall error rate typically goes down with deliberation. And blanket objections to attributing some scientific and civic status to deliberative forums beg the question, since the claim is that DOps deserve such status. It is only with the interaction of these factors that a truly major problem emerges. And, even then, if public officials and members of the public can find a way to distinguish between rigged deliberation and high-quality forums, then the problem becomes much less acute (Neblo et al. 20I0).

Presumably something like this last thought led Fishkin to trademark "Deliberative Opinion Polls," settle on a high degree of uniformity in their features, and rely on a relatively small set of trusted insiders to design, execute, and analyze them. He has been criticized for all of this, but tight, proprietary branding and a program for quality control linked to that brand are the obvious ways to distinguish Dops from those who might want to highjack the process, or at least muddy the waters. The problem, though, is that proprietary branding and insularity end up displacing the locus of democratic worries onto the brand itself.

Anyone organizing a deliberative forum has a legitimate need to appropriately delimit the scope of the deliberations and insulate the background materials from manipulation and bias, for example. Yet we would need some set of procedures for warranting that these goals were adequately accomplished. Since the relevant procedural standards are democratic procedures, the whole idea of a proprietary brand starts to become functionally paradoxical if pressed too far. Technocratic responses to democratic problems cannot be technocratic all the way down, even (or perhaps especially) when they claim to be technologies of democracy.

In this specific and limited sense, I agree with Gleason that Dops might reasonably be subjected to strict scrutiny. In trying to fend off one set of problems, reformers can easily create another. Without carefully embedding deliberative forums in a larger system of transparent democratic contestation, practitioners are sure to induce a "legitimation crisis" in representations of deliberative public opinion even if they have all of the properties claimed for them (e.g., high-quality samples, insulation from special interests, a wide range of expert input, free and fair deliberative exchanges, etc.). ${ }^{4}$

All deliberative forums, then, face a deep tension in application: They must remain democratically accountable to the broader political system 
without becoming assimilated to it. The danger of assimilation comes in three principle forms. First, as noted above, if specific deliberative forums are too democratically endogenous - if everything is up for grabs locally - then they may not be able to provide much distinctive value vis-à-vis the broader political system. For example, I once attended a forum about how best to manage the privacy of medical records while also promoting potentially life-saving research. One of the sessions evolved into a completely different discussion because one of the participants believed that the U.S. government had bioengineered the AIDS virus and deliberately introduced it into the African-American community as part of a eugenics initiative. Such arguments should be given a hearing in the broader political system. Some conspiracy theories turn out to be true (this man cited the Tuskegee experiment as precedent to motivate his argument), and some initially fringe ideas eventually become common wisdom. But in the context of specific deliberative forums, allowing every such issue that comes up to dominate the discussion, in effect, dissolves deliberative forums back into the larger political discourse. If so, then familiar problems of scale, complexity, motivation, and competence return. Deliberative opinion loses its focus and its distinct normative potential.

Thus, even as they try to remain democratically accountable, organizers must circumscribe the scope, form, content, and procedures of deliberative forums to maintain the forums' coherence and distinctive role in the larger political system. But doing so opens the door to the second principal form of becoming assimilated to the broader political system: strategic cooptation by elites (and, less acutely, their inadvertent biases). As I argued above, if deliberative forums become more important in democratic politics, they are also sure to become high-priority targets for strategic manipulation. So there are good reasons to worry about whether our knowledge of how mini-publics have worked to date can serve as a reliable guide for a more deliberatively empowered future.

However, the obvious way to remain democratically accountable while providing adequate resistance to bias and strategic manipulation is to expose every element of the process to public review and criticism. Thus, despite my specific disagreements with some of Gleason's arguments, I consider her efforts at contestation, and this exchange more generally, to be an essential part of alleviating the dialectical tendencies toward deliberative democracy's own version of a legitimation crisis. Critics such as Gleason play a crucial role by standing in for 
the demos, monitoring for strategic cooptation, inadvertent bias, etc. Deliberative practitioners should welcome such critique, and even encourage it.

However, there remains at least one more dialectical turn of the screw. Even if vigorous public review and criticism can help prevent strategic actors from capturing deliberative forums (or exposing them when they do), those actors will still have strong incentives to prevent deliberative opinion from overcoming their advantage in the broader political system. That is, even if they cannot add to their power by coopting deliberative opinion, they will seek to neutralize any deliberative effects adverse to their interests. And, ironically, facilitating vigorous public review and criticism provide ideal means to do so. Precisely to the extent that public review and criticism is open and vigorous, interested actors can feign the role of the social critic to muddy the waters and "jam" any signals unfavorable to their position (Minozzi 2OII).

In principle, such a process may be self-correcting. Perhaps the cure for the ills of democracy is more democracy. But then we are thrown back on a second-order version of the problems of scale, complexity, motivation, and citizen competence in mass democracy that deliberative forums were supposed to alleviate in the first place. Displacing those problems onto another level may attenuate them, but it hardly eliminates them.

So to summarize: Deliberation's "legitimation crisis" emerges from an initial dilemma, one of the horns of which then branches off into a trilemma. Deliberative forums must remain democratically accountable to the larger political system without being assimilated to it. Democratic accountability pushes deliberative forums to become more internally democratic, but that risks making them too diffuse and chaotic, at which point they begin to dissolve back into the broader political discourse. So someone needs to make decisions about structure, content, and limits to the process, and such decisions risk cooptation, bias, and strategic manipulation (or a retreat from democratic accountability). Vigorous public review and criticism can help, but it opens the door to strategic jamming, which makes it difficult and costly for the public to differentiate between high-quality deliberation and manipulated opinion, thus recapitulating the first-order dilemmas of mass democratic politics. I see no general solution to this interlocking series of dilemmas, and on theoretical grounds, I doubt that one exists. 
This argument is not meant as a counsel of despair. It is only intended to establish that we cannot reasonably expect mini-public forums (DOPs or other versions) to serve as a miracle cure for what ails mass democracy. Doing so asks too much of them, but more importantly it also misunderstands their role and real potential in the larger deliberative system of democracy.

Deliberative forums are the most promising institutional innovation in recent memory. However, by understanding the structure of the tradeoffs that deliberative forums face, we can make more sensible choices about how to embed them in the larger deliberative system of democracy, and about how to adapt them to various functions within that system. What I called a dilemma is not a true dilemma; or rather it only appears as such in the abstract. In practice, some elements of the problem may be less acute or easier to ameliorate than others, so that we would have good reasons to favor concessions in one area rather than another.

Indeed, we already know a fair bit about which problems are likely to be more acute in various circumstances, and how we might experiment with institutional variations to further realize the potential of deliberative forums. For example, the tension between democratic accountability and adequate structure to make forums coherent need not be resolved in one go. Organizers could distribute the burden of accountability across time and participants. Rather than moving from organizers and experts to citizen forums in one step, we could begin a project with very informal, unstructured brainstorming or focus-group-style input from citizens, organize pilot forums designed to elicit feedback and criticism, and only then run the main forums in light of democratic input, accountability, and contestation along the way.

It is hardly fanciful to expect criticism and contestation from average citizens, if it is sincerely elicited by the organizers. I once helped organize a project in which groups within the pilot forums unanimously rejected the original set of policy choices that the experts and organizers worked up, generating an entirely new and very attractive option that went on to win plurality support in the main forums (Damschroder et al. 2007). Moreover, forum participants and a fresh sample of citizens could be recruited to evaluate and criticize the process and organize reports on the forums ex post as well. Thus, relatively simple procedures could be used to maintain robust democratic accountability throughout the process without the forums degenerating into a free-for-all. 
The anecdote about participants in our pilot project resisting the original elite-determined set of choices illustrates an important caveat. While it is reasonable to worry about elite manipulation to a point, we should not sell citizen participants short. Participants can and do resist the information, frames, and other elements provided for them in deliberative forums. For example, progressive critics pre-emptively attacked a recent America Speaks forum on the federal budget deficit, accusing one of its sponsors of rigging the briefing materials and response formats. Yet the participants ended up moving sharply toward a package of policies favored by progressives. Whether one believes that this forum's design was an active attempt at manipulation, a case of inadvertent bias, or a reasonable choice among many in presenting the options, the frame, and format were hardly destiny. The social critic's reasonable concern about protecting citizens from elite manipulation can easily devolve into a well-intentioned elitism of its own, treating their fellow citizens as dupes or children incapable of independent critical thought. ${ }^{5}$

Critics reasonably worry that biases in the background information presented in deliberative sessions may unduly influence participants. Yet there are good reasons to believe that participants are hardly passive receptacles, waiting for organizers to tell them what is true and what to do. A recent study (Esterling et al. 20I I), for example, found a distinct and substantial deliberative effect on gains in policy specific factual knowledge. That is, participating in deliberation induced knowledge gains beyond those realized by participants randomly selected to receive only the background materials. Crucially, however, those distinct knowledge gains were not driven by the content of the deliberative sessions themselves, but rather by living in their shadow. People who knew that they were going to confront experts and deliberate with their fellow citizens trained up in anticipation by seeking out more information about the topic (and politics more generally) on their own. Far from merely waiting to be told what was important about the topic, participants wanted to judge for themselves whether the information was balanced, and chose to talk to friends, consult trusted sources of information, and otherwise plug into the larger, lessregulated deliberative system. Such external preparation would make it much harder to distort deliberative opinion. 
New problems with applied deliberation are sure to emerge. The tensions internal to deliberative legitimation admit of no general, permanent solution. Any future deliberative research or reforms should be and will be subjected to vigorous criticism and debate as exemplified in this forum. Indeed, such debate is an essential part of any deliberative democratic system worth the name.

\section{NOTES}

I. To some extent Gleason and Fishkin may be talking past each other here. In the quoted passage, one can read her as arguing that the group analyses are irrelevant to ruling out the malignant effects of garrulousness, articulateness, charisma, not that they are irrelevant per se. But that is to miss the forest for the trees by ignoring the enormous importance of what the group results show, and focusing on dramatically less important criteria. There is not obviously anything normatively problematic about variation in rates of talkativeness, for example, unless they can be linked to something that is presumptively bad. At worst, influence linked to variation around talkativeness per se would constitute a kind of random error from a moral or political point of view, and one cannot reasonably expect deliberation to have no such random variation. Moreover, it might actually represent a good thing, if people with ex ante minority views talk more often, or those representing what political scientists call "hard" rationales do so, etc. The problem is much more serious if it is wealthy, educated, white, men who are doing most of the talking, and, in turn, having much of the influence. But Fishkin and others show that in deliberation these groups usually have either no effect, or are smaller than in most other domains of social interaction. The same would go for articulateness and charisma, with the added unfairness (in burden of proof) that objections based on these proto-concepts do not have the ready, valid, operational indicators that talkativeness does.

2. On a strict scrutiny standard it might be reasonable to rely on scare quotes to induce doubt by merely prompting us to recognize that some term or concept may be contestable, ambiguous, or ambivalent. In my view, though, the scare quotes end up doing too much of the critical work here, since they are seldom accompanied by a substantial discussion of how we should better understand the contested term or concept.

3. I discuss these issues at greater length in Neblo n.d.

4. Habermas's 1975 book Legitimation Crisis revises standard Marxist theory by laying out what he sees as the distinct crisis tendencies in welfare-state capitalism. His discourse theory of law and democracy (1996) was developed as an alternative model of legitimation that tries to avoid these processes. Since his theory does not lean as heavily on organized deliberative forums as Fishkin's does, it is not clear that my critique here speaks to deliberative democracy more generally.

5. Some of the Internet and blog-based attacks in this episode were, in my view, savagely unfair to the organizers and condescending to the citizen-participants, 
amounting to a pre-emptive attempt at "jamming" the results. Benjamin Page and Lawrence Jacobs (2010) released a much more temperate and scholarly white paper pressing similar arguments. I disagree with some of their claims, but they did raise reasonable concerns. For example, one of the key survey questions about how much to cut the deficit started at zero and moved up from there, even though many reasonable people having been arguing that, in the context of the recession, we should actually be increasing deficit spending, at least temporarily (e.g., Paul Krugman has been pressing this argument repeatedly for the last two years).

\section{REFERENCES}

Damschroder Laura J., Joy L. Pritts, Michael A. Neblo, Rosemarie J. Kalarickal, John W. Creswell, and Rodney A. Hayward. 2007. "Patients, Privacy and Trust: Patients' Willingness to Allow Researchers to Access their Medical Records." Social Science \& Medicine 64(I): 223-35.

Esterling, Kevin M., Michael A. Neblo, and David M. J. Lazer. 20I I. "Means, Motive, and Opportunity in Becoming Informed About Politics: A Deliberative Field Experiment with Members of Congress and Their Constituents." Public Opinion Quarterly 75(3): 483-503.

Gleason, Laurel. 20II. "Revisiting The Voice of the People: An Evaluation of the Claims and Consequences of Deliberative Polling." Critical Review 23(3): $37 \mathrm{I}-92$.

Habermas, Jürgen. 1975. Legitimation Crisis. Boston, Mass.: Beacon Press.

Habermas, Jürgen. 1996. Between Facts and Norms: Contributions to a Discourse Theory of Law and Democracy. Cambridge, Mass.: MIT Press.

Lippmann, Walter. 1922. Public Opinion. New York: Harcourt, Brace.

Minozzi, William. 20II. "A Jamming Theory of Politics." Journal of Politics 73: $30 \mathrm{I}-\mathrm{I} 5$.

Neblo, Michael A. n.d. Common Voices: Between the Theory and Practice of Deliberative Democracy. Manuscript.

Neblo, Michael A. 2000. Thinking Through Democracy: Deliberative Politics in Theory and Practice. Ph.D. diss., University of Chicago.

Neblo, Michael A. 2005. "Change for the Better? Linking the Mechanisms of Deliberative Opinion Change to Normative Theory." Paper presented at the 2005 Annual Meeting of the Midwest Political Science Association, Chicago, Ill.

Neblo, Michael A., Kevin Esterling, Ryan Kennedy, David Lazer, and Anand Sokhey. 20I0. "Who Wants to Deliberate-and Why?" American Political Science Review I04(3): 566-83.

Page, Benjamin, and Lawrence Jacobs. 20I0. "Understanding Public Opinion on Deficits and Social Security." Roosevelt Institute Working paper No. 2. 